\title{
Actual use of a front-of-pack nutrition logo in the supermarket: consumers' motives in food choice
}

\author{
Ellis L Vyth ${ }^{1, *}$, Ingrid HM Steenhuis ${ }^{1}$, Jessica A Vlot ${ }^{1}$, Anouk Wulp ${ }^{1}$, \\ Meefa G Hogenes ${ }^{1}$, Danielle H Looije ${ }^{1}$, Johannes Brug ${ }^{2}$ and Jacob C Seidell ${ }^{1,2}$ \\ 'Department of Health Sciences and the EMGO Institute for Health and Care Research, VU University \\ Amsterdam, De Boelelaan 1085, 1081 HV Amsterdam, The Netherlands: ${ }^{2}$ Department of Epidemiology \\ and Biostatistics, EMGO Institute for Health and Care Research, VU University Medical Center, Amsterdam, \\ The Netherlands
}

Submitted 8 June 2009: Accepted 17 February 2010: First published online 1 April 2010

\begin{abstract}
Objective: A front-of-pack nutrition logo on products with relatively favourable product compositions might help consumers to make more healthful choices. Studies investigating actual nutrition label use in point-of-purchase settings are scarce. The present study investigates the use of the 'Choices' nutrition logo in Dutch supermarkets.

Design: Adults were asked to complete a validated questionnaire about motivation for food choice and their purchased products were scored for the Choices logo after they had done their shopping.

Setting: Nine supermarkets in The Netherlands.

Subjects: A total of 404 respondents participated.

Results: Of the respondents, $62 \%$ reported familiarity with the logo. The motivations for food choice that were positively associated with actually purchasing products with the logo were attention to 'weight control' and 'product information'. The food choice motive 'hedonism' was negatively associated with purchasing products with the logo.

Conclusions: This is the first study to investigate actual use of the Choices logo. In order to stimulate consumers to purchase more products with a favourable product composition, extra attention should be paid to hedonistic aspects such as the tastefulness and the image of healthy products.
\end{abstract}

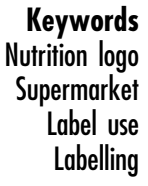

Keywords Nutrition logo Label use Labelling
The high levels of trans fatty acids, SFA, salt and sugars in the European diet are associated with a higher risk of diet-related chronic diseases ${ }^{(1)}$. In order to encourage consumers to adopt more healthful eating habits, insight into which motives influence consumer food choices is necessary ${ }^{(2)}$. Different motives have been identified such as taste, mood, convenience, price, weight control, habitual behaviour and pleasure ${ }^{(2-5)}$. Health motives may also influence food choices ${ }^{(6,7)}$.

However, interpreting the overload of nutritional information currently available appears to be a difficulty for consumers trying to make healthy food choices ${ }^{(8,9)}$. A frontof-pack nutrition logo on products with a favourable product composition as compared with similar products within the same product category could help consumers to make healthy choices, thereby possibly reducing the prevalence of diet-related chronic disease ${ }^{(9-12)}$.

Many countries have developed their own frontof-pack nutrition logos, which vary in design and complexity. One of the front-of-pack nutrition logos currently available in The Netherlands is the 'Choices' logo ('Ik Kies Bewust' logo, see Fig. 1). This logo has been introduced by a collaboration of various partners, and can be found on a variety of brands in many supermarket chains, worksite cafeterias and other food service locations across The Netherlands. The logo is assigned to products that contain lower levels of sodium, added sugar, SFA, trans fatty acids and energy and increased levels of fibre as compared with similar products within the same product category. Table 1 shows the number of available products carrying the Choices logo per product category. The items are mutually exclusive. The logo is supported by a foundation of food manufacturers, retail and food service organizations and nutrition scientists, and is conditionally endorsed by the Dutch Government. The criteria of the Choices logo have been developed by an independent scientific committee of nutrition and food scientists. A detailed background to the Choices logo has been described elsewhere $^{(13,14)}$. Earlier research showed that consumers were largely familiar with the Choices logo one year after its introduction. Women perceived the logo to be 


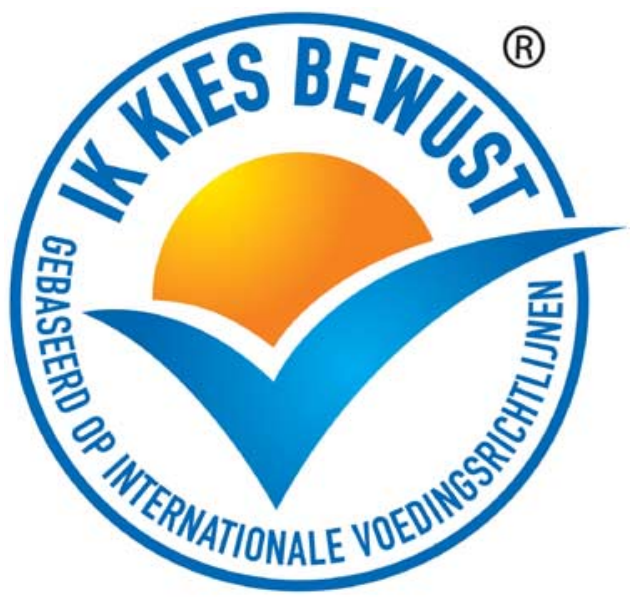

Fig. 1 The Ik Kies Bewust ('Choices') nutrition logo

Table 1 Number of available products carrying the Choices logo per product category

\begin{tabular}{lc}
\hline Product category & $\begin{array}{c}\text { Number of available } \\
\text { logo products }\end{array}$ \\
\hline Fruits and vegetables & 703 \\
Sources of carbohydrates & 183 \\
Sources of proteins & 277 \\
Dairy products & 285 \\
Oils and fats & 202 \\
Ready-to-eat dishes & 65 \\
Soups & 355 \\
Sauces & 199 \\
Snacks & 195 \\
Beverages & 333 \\
Remaining products & 102 \\
\hline
\end{tabular}

more credible and attractive than did men. Furthermore, consumers more interested in health were more likely to report that they used the logo when shopping for food $^{(13)}$.

However, until now, the actual use of the Choices logo has not been investigated in real-life settings such as supermarkets. Only a few studies have investigated the use of a nutrition logo in the supermarket itself ${ }^{(15-17)}$. In general, there is a large need for studies in which the use of nutrition labels is investigated in point-of-purchase settings $^{(8,9,13,18-20)}$.

The aim of the present study was to provide insights into the use of the Choices logo in the supermarket. Reported logo use was explored by a questionnaire and actual logo use was investigated by verifying actual product purchases after participants had done their shopping. Also, the motives for choice of food of consumers, both health and other food choice motives, were explored. It was investigated whether or not a relationship exists between:

1. demographic variables of consumers and familiarity with, and actual use of, the Choices logo;

2. reported logo use and actual logo use;

3. motives for food choice and logo use.

\section{Methods}

\section{Design and participants}

A total of 1089 consumers were asked to participate in the supermarket setting, after they had done their shopping, of which 404 participants were willing to cooperate (response rate $37 \%$ ). Inclusion criteria were age $\geq 18$ years and having a shopping basket or cart with products after finishing shopping. The main reason for refusing to participate was lack of time. Participants were recruited in nine supermarkets of various sizes all belonging to the C1000 supermarket chain, one of the largest supermarket chains in The Netherlands. The supermarkets were located in different socio-economic areas spread over six different cities in the western part of The Netherlands. Data collection took place from Monday until Saturday, including evening hours, across a 3 -week time period. While participants were completing a questionnaire, four trained research assistants counted the products the participants had just bought and whether the products were carrying the Choices logo or not. All participants gave informed consent.

\section{Questionnaire}

The questionnaire started with questions about age, gender, body weight and height, level of education and frequency of shopping in a supermarket. Next, the questionnaire included the Dutch version of the Food Choice Questionnaire (FCQ), a generally used instrument for measuring motives related to food choice, developed by Steptoe et $a l .{ }^{(2)}$. The FCQ has been validated and has been found to be reliable, consistent and stable over time ${ }^{(2,21-23)}$. The FCQ measures nine motivations identified as being related to food choices, namely: 'health', 'mood', 'convenience', 'sensory appeal', 'natural content', 'price', 'weight control', 'familiarity' and 'ethical concern'. The FCQ begins with the sentence 'It is important to me that the food I eat on a typical day...' and is then followed by a total of thirty-six statements covering the nine food choice motives measured by the FCQ, all measured using a 4-point Likert scale. For example, for an item concerning the weight control motive: 'It is important to me that the food I eat on a typical day helps me to control my weight' (response categories ranging from $1=$ 'not at all important' to $4=$ 'very important'). As ethical concern related to environmental and political issues was not considered to provide useful information related to the Choices logo, this motive was omitted. Three additional motives of potential interest regarding the Choices logo were included in the questionnaire. Two were derived from the food-related lifestyle instrument (FRL), a questionnaire extensively tested and shown to be stable across cultures and over time ${ }^{(3,5)}$ : 'importance of product information' and 'use of a shopping list'. Further, the food choice motive 'importance of pleasure' (hedonism) was $\operatorname{added}^{(7)}$. Each of the last three motives was measured 
by three statements on a 7-point Likert scale. For example, 'I compare labels to select the most nutritious food' (response categories ranging from $1=$ 'totally disagree' to $7=$ 'totally agree'). The last part of the questionnaire included three questions about the Choices logo, concerning familiarity with the logo ('Do you know the Choices logo?'; response categories 'yes' or 'no') and use of the Choices logo ('Did you buy products with the Choices logo today intentionally?'; response categories 'yes' or 'no' and 'How often do you purchase products with the Choices logo intentionally?'; response categories ranging from $1=$ 'never' to $5=$ 'always').

\section{Product observations}

Product selections were verified by the trained research assistants after the participants had done their shopping. All products the participants had just bought in the supermarket were scored. The products were classified into the product categories for which the Choices criteria have been defined: fruits and vegetables, sources of carbohydrates, sources of proteins (meat, fish, eggs and meat substitutes), dairy products, oils and fats, ready-toeat dishes, soups, sauces, snacks, beverages, and remaining products. The research assistants classified each product in the right product category and noted whether it was carrying the Choices logo or not.

\section{Calculations}

From self-reported body weight and height, BMI was calculated $\left(\mathrm{kg} / \mathrm{m}^{2}\right)$ and divided into three categories: $\mathrm{BMI}<25 \mathrm{~kg} / \mathrm{m}^{2}$ (healthy weight), $\mathrm{BMI}=25-30 \mathrm{~kg} / \mathrm{m}^{2}$ (overweight) and $\mathrm{BMI} \geq 30 \mathrm{~kg} / \mathrm{m}^{2}$ (obese). Educational level was divided into three categories: a low educational level (primary school or basic vocational education), a medium educational level (secondary vocational education or high-school degree) or a high educational level (higher vocational education or university degree), corresponding to the commonly used classification in The Netherlands ${ }^{(24)}$. Self-reported frequency of buying products with the Choices logo was also divided into three categories: 'never or seldom', 'sometimes' and 'often or always'.

A mean score (range: 1-4) was calculated for each motive included in the $\mathrm{FCQ}^{(2,22)}$, and for importance of product information, shopping list and importance of pleasure (range: $1-7)^{(5)}$. The numbers of observed products purchased with the logo were added up, both for the whole study population and per person. The variables are expressed as absolute numbers (number of actual purchased products with logo) and as a proportion (percentage of actual purchased products with logo out of the total number of purchased products). Additionally, the same variables were calculated excluding fresh fruits and vegetables, because although all fruits and vegetables comply with the criteria for having the logo, many fresh fruits and vegetables are not labelled as such.

\section{Statistical analyses}

Demographics, familiarity and actual logo use

Descriptive analysis was used to report the demographic variables of the participants. The $\chi^{2}$ test, $t$ test and ANOVA (using Bonferroni adjustment for multiple comparisons) were used to test for differences in familiarity with the logo and actual logo use according to gender, BMI and educational level.

\section{Reported logo use v. actual logo use}

The $t$ test was used to explore differences in actual logo use between respondents who did and who did not report purchasing products with the Choices logo intentionally.

\section{Food choice motives and logo use}

The reliability of the food choice motives was tested using Cronbach's $\alpha$. ANOVA was used to examine significant differences in food choice motives according to reported use of the Choices logo. Bonferroni adjustment for multiple comparisons was applied. A backward selection procedure was furthermore used to obtain the best linear regression model, using reported logo use and proportion of products with the logo as the dependent variables. The independent variables tested were age, gender, BMI, educational level and the food choice motives. Store was also included as an independent variable to adjust for the possible clustering effect of store.

Statistical analyses were performed using the SPSS statistical software package version $15 \cdot 0$ (2006; SPSS Inc., Chicago, IL, USA), adopting a significance level of $0 \cdot 05$. For the linear regression model an exclusion $P$ value of $0 \cdot 10$ was used.

We performed all analyses using both the proportion variable including and excluding fresh fruit and vegetables to be able to check for any bias. As we found no differences in all results between the two variables, we only discuss both proportion variables in the first paragraph of the Results section. In the rest of the paper we report the proportion variable including fresh fruit and vegetables.

\section{Results}

\section{Demographics, familiarity and actual logo use}

The research population consisted of 404 consumers, $79 \cdot 2 \%$ women; mean age $50 \cdot 0$ (SD $14 \cdot 2$ ) years (range: 18-84 years). Table 2 shows familiarity with the Choices logo and the proportion of purchased products with a logo out of the total number of purchased products (both including and excluding fresh fruit and vegetables) for subgroups based on gender, BMI and educational level. Sixty-two per cent of the total population reported familiarity with the logo. Women were more familiar with the logo than men $(P<0 \cdot 01)$. Familiarity was significantly different between the different levels of education $(P<0 \cdot 01)$. Furthermore, participants with a high and a 
low educational level purchased relatively fewer products with the logo than did participants with a medium educational level, both including and excluding fresh fruit and vegetables (all $P<0 \cdot 01$ ). No other significant differences were found.

\section{Product observations}

Figure 2 provides insight into the product observations made for every product category. A total of 7281 products were scored. Most products carrying the logo (expressed as a percentage of the total number of products scored within a product category) were found to be in the category of dairy products $(42 \cdot 2 \%)$, followed by oils and fats $(41 \cdot 8 \%)$, vegetables and fruits $(33 \cdot 4 \%)$, and soups $(30 \cdot 3 \%)$.

\section{Reported logo use v. actual logo use}

Table 3 shows that participants who reported to intentionally purchase products with the logo, also actually purchased more products with the logo than participants who reported not purchasing products with the logo intentionally (both absolute and as a proportion of total products bought; $P<0 \cdot 01)$.

\section{Food choice motives and reported logo use}

Table 4 shows the mean scores of the total population ( $n$ 404) for each of the food choice motives, and the food choice motives separately calculated for different levels of reported logo use (of those familiar with the logo, $n$ 247). Further, the Cronbach's $\alpha$ values of the food choice motives are listed. The more often participants reported purchasing products with the logo, the higher they scored on the food choice motives product information, health and weight control (all $P<0 \cdot 01$ ). Also, participants who reported 'often or always' purchasing products with the Choices logo had a higher mean score on mood (important that food makes them feel good), natural content and familiarity with food than participants who reported 'never or seldom' purchasing products with the logo (all $P<0 \cdot 01$ ).

It can be concluded from the regression analyses that the food choice motives positively associated with reported logo use were weight control $(\beta=0 \cdot 26,95 \%$ CI $0 \cdot 09,0 \cdot 43$,

Table 2 Familiarity with the Choices logo and actual purchasing behaviour of the study population: participants aged $\geqslant 18$ years recruited in nine supermarkets of the $\mathrm{C} 1000$ supermarket chain, from different socio-economic areas spread over six different cities in the western part of The Netherlands

\begin{tabular}{|c|c|c|c|c|c|}
\hline & \multirow[b]{2}{*}{ Familiarity with logo (\%) } & \multicolumn{2}{|c|}{$\begin{array}{c}\% \text { of actual purchased products } \\
\text { with logo out of total number of } \\
\text { purchased products }\end{array}$} & \multicolumn{2}{|c|}{$\begin{array}{l}\% \text { of actual purchased products with logo out } \\
\text { of total number of purchased products: } \\
\text { without fresh fruit and vegetables }\end{array}$} \\
\hline & & Mean & SD & Mean & SD \\
\hline Total (n 404) & $62 \cdot 0$ & $18 \cdot 0$ & $15 \cdot 2$ & $16 \cdot 6$ & $16 \cdot 2$ \\
\hline Men $(n$ 84) & $35 \cdot 4$ & $17 \cdot 4$ & $15 \cdot 4$ & $16 \cdot 0$ & $16 \cdot 1$ \\
\hline Women (n 320) & $68 \cdot 9^{* *}$ & $18 \cdot 2$ & $15 \cdot 2$ & $16 \cdot 8$ & $16 \cdot 2$ \\
\hline \multicolumn{6}{|l|}{ BMI $\left(\mathrm{kg} / \mathrm{m}^{2}\right)$} \\
\hline$<25(n 201)$ & $64 \cdot 3$ & $18 \cdot 9$ & $14 \cdot 5$ & $17 \cdot 5$ & $15 \cdot 8$ \\
\hline $25-30(n$ 135) & $54 \cdot 9$ & $17 \cdot 1$ & $15 \cdot 8$ & $15 \cdot 6$ & $16 \cdot 5$ \\
\hline$\geq 30(n 61)$ & $68 \cdot 9$ & $16 \cdot 3$ & $16 \cdot 4$ & $15 \cdot 7$ & $16 \cdot 8$ \\
\hline \multicolumn{6}{|l|}{ Educational level } \\
\hline Low (L) (n 130) & $52 \cdot 0$ & $16 \cdot 0$ & $15 \cdot 3$ & $14 \cdot 9$ & $17 \cdot 4$ \\
\hline Medium (M) ( $n$ 147) & $66 \cdot 0$ & $21 \cdot 5^{\mathrm{M}>\mathrm{L} * \star}$ & $16 \cdot 4$ & $20 \cdot 6^{\mathrm{M}>\mathrm{L} \star \star}$ & $16 \cdot 7$ \\
\hline High $(H)(n$ 123) & $68 \cdot 0^{*}$ & $15 \cdot 9^{\mathrm{H}<\mathrm{M}_{\star \star}}$ & $12 \cdot 6$ & $13 \cdot 5^{\mathrm{H}<\mathrm{M}_{\star *}}$ & $13 \cdot 0$ \\
\hline
\end{tabular}

Significance: ${ }^{\star} P<0.05,{ }^{\star *} P<0.01$.

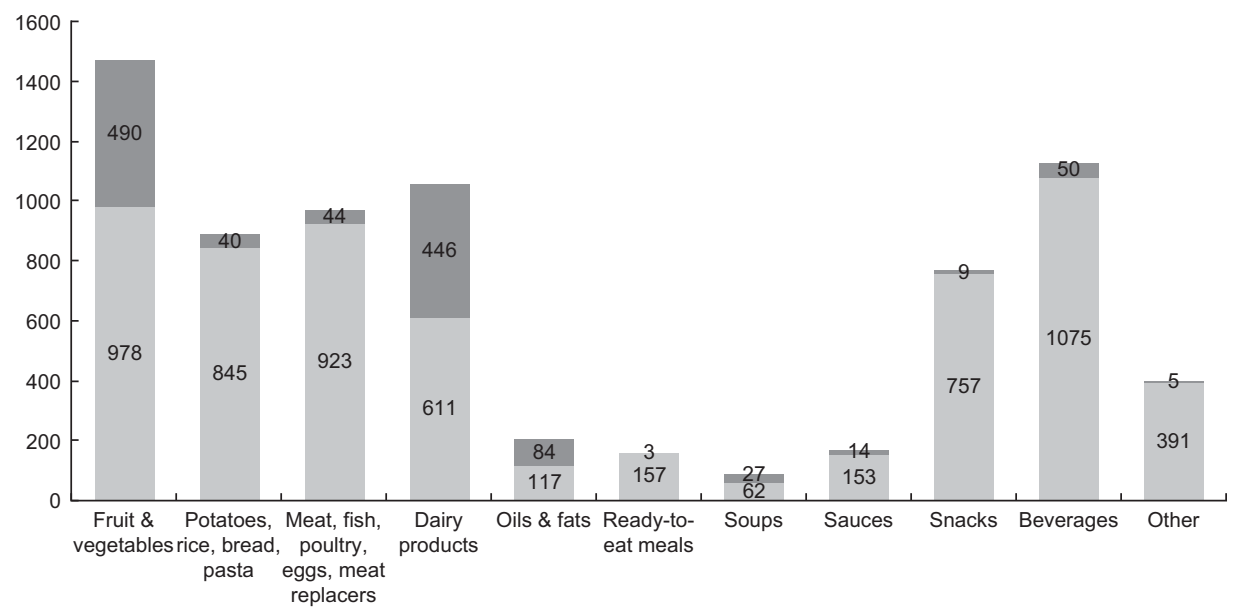

Fig. 2 Total number (amount) of purchased products with ( $\square$ ) and without ( $\square$ ) the Choices logo per product category 
Table 3 Reported and actual logo use of all participants who were familiar with the Choices logo ( $n$ 246)

\begin{tabular}{|c|c|c|c|c|}
\hline & \multicolumn{2}{|c|}{$\begin{array}{l}\text { Reported purchasing } \\
\text { products with logo }(n 72)\end{array}$} & \multicolumn{2}{|c|}{$\begin{array}{l}\text { Reported not purchasing } \\
\text { products with logo ( } n \text { 174) }\end{array}$} \\
\hline & Mean & SD & Mean & SD \\
\hline Number of actual purchased products with logo (range: 0-20) & $3 \cdot 96^{\star \star}$ & $2 \cdot 85$ & $2 \cdot 77$ & $2 \cdot 53$ \\
\hline $\begin{array}{l}\text { Actual purchased products with logo as \% of total number of } \\
\text { purchased products (range: } 0-100 \text { ) }\end{array}$ & $23 \cdot 65^{\star \star}$ & $16 \cdot 99$ & $17 \cdot 19$ & $13 \cdot 82$ \\
\hline
\end{tabular}

Significance: ${ }^{\star *} P<0 \cdot 01$.

Table 4 Food choice motives of the complete study population ( $n$ 404), food choice motives related to reported logo use (significant relationships only) of those being familiar with the Choices logo ( $n$ 247), and Cronbach's $\alpha$ values

\begin{tabular}{|c|c|c|c|c|c|c|c|c|c|}
\hline & & & \multicolumn{6}{|c|}{ Reported logo use } & \multirow[b]{3}{*}{ Cronbach's $\alpha$} \\
\hline & \multicolumn{2}{|c|}{$\begin{array}{l}\text { Total } \\
\text { (n 404) }\end{array}$} & \multicolumn{2}{|c|}{$\begin{array}{l}\text { Never or seldom (1) } \\
\qquad(n 57)\end{array}$} & \multicolumn{2}{|c|}{$\begin{array}{l}\text { Sometimes (2) } \\
\quad(n 114)\end{array}$} & \multicolumn{2}{|c|}{$\begin{array}{l}\text { Often or always (3) } \\
\qquad(n 76)\end{array}$} & \\
\hline & Mean & SD & Mean & SD & Mean & SD & Mean & SD & \\
\hline Health (range: $1-4$ ) & $3 \cdot 13$ & 0.45 & $2 \cdot 94$ & $0 \cdot 41$ & $3 \cdot 14^{2>1 * *}$ & $0 \cdot 40$ & $3 \cdot 33^{3>2,3>1 * *}$ & 0.43 & $0 \cdot 76$ \\
\hline Mood (range: $1-4$ ) & $2 \cdot 52$ & 0.63 & $2 \cdot 27$ & 0.53 & $2 \cdot 50$ & 0.63 & $2 \cdot 68^{3>1 \star \star}$ & 0.63 & 0.83 \\
\hline Convenience (range: 1-4) & $2 \cdot 86$ & 0.59 & & & & & & & $0 \cdot 75$ \\
\hline Sensory appeal (range: $1-4$ ) & $3 \cdot 14$ & 0.50 & & & & & & & 0.66 \\
\hline Natural content (range:1-4) & $2 \cdot 88$ & 0.64 & $2 \cdot 64$ & 0.64 & $2 \cdot 89$ & 0.57 & $3 \cdot 12^{3>1 \star \star}$ & 0.64 & $0 \cdot 77$ \\
\hline Price (range: $1-4$ ) & 3.00 & 0.61 & & & & & & & 0.69 \\
\hline Weight control (range: $1-4$ ) & $2 \cdot 99$ & 0.66 & $2 \cdot 70$ & 0.56 & $3 \cdot 03^{2>1 \star \star}$ & $0 \cdot 61$ & $3 \cdot 29^{3>1 \star \star}$ & 0.64 & $0 \cdot 80$ \\
\hline Familiarity with food (range: $1-4$ ) & $2 \cdot 40$ & 0.58 & $2 \cdot 13$ & 0.55 & $2 \cdot 34$ & $0 \cdot 60$ & $2 \cdot 56^{3>1 * *}$ & 0.59 & 0.57 \\
\hline Product information (range: $1-7$ ) & $4 \cdot 44$ & $1 \cdot 48$ & $3 \cdot 70$ & $1 \cdot 45$ & $4 \cdot 60^{2>1 \star *}$ & $1 \cdot 17$ & $5 \cdot 60^{3>2,3>1 \star \star}$ & $1 \cdot 22$ & $0 \cdot 83$ \\
\hline Shopping list (range: $1-7$ ) & $4 \cdot 87$ & $1 \cdot 83$ & & & & & & & $0 \cdot 86$ \\
\hline Hedonism (range: $1-7$ ) & $4 \cdot 90$ & 0.79 & & & & & & & 0.60 \\
\hline
\end{tabular}

Significance: ${ }^{* *} P<0 \cdot 01$.

$P=0 \cdot 002), \quad$ familiarity $(\beta=0 \cdot 25, \quad 95 \%$ CI $0 \cdot 08, \quad 0 \cdot 42$, $P=0 \cdot 004)$ and product information $(\beta=0 \cdot 31,95 \%$ CI 0.23 , $0 \cdot 38, P=0 \cdot 000)$. Shopping list was negatively associated with reported logo use $(\beta=-0 \cdot 08,95 \%$ CI $-0 \cdot 13,-0 \cdot 02$, $P=0 \cdot 007)$.

\section{Food choice motives and actual logo use}

Food choice motives positively associated with actual purchasing of products with the logo were weight control $(\beta=3.05,95 \%$ CI $0.56,5 \cdot 54, P=0.017)$ and product information $(\beta=1 \cdot 80,95 \% \mathrm{CI} 0 \cdot 68,2 \cdot 92, P=0 \cdot 002)$. The food choice motive hedonism was negatively associated with purchasing products with the $\operatorname{logo}(\beta=-2 \cdot 53,95 \%$ CI $-4 \cdot 55,-0 \cdot 51, P=0 \cdot 01)$.

\section{Discussion}

Studies investigating the role of nutrition logos in guiding buying decisions in point-of-purchase settings such as supermarkets are scarce ${ }^{(8,9,13,16,18-20)}$. This is the first study to investigate in the supermarket the actual use of the Dutch Choices logo, a front-of-pack nutrition logo on products with a favourable product composition.

\section{Familiarity and logo use}

Familiarity with the Choices logo in the present study was lower than reported in our earlier research, in which $88.4 \%$ of the population was familiar with the $\operatorname{logo}^{(13)}$. This can be explained by the fact that, in contrast to our previous study, we did not use an image of the logo in the questionnaire. Nevertheless, $62 \%$ of the study population reported being familiar with the logo, more so among women and more highly educated participants. This is in line with results from earlier studies investigating nutrition $\operatorname{logos}{ }^{(9,25-29)}$.

\section{Product observations}

The product observations from the present study showed that most products bearing the logo were found to be in the category of dairy products followed by oils and fats, vegetables and fruits, and soups. These findings are not surprising, as large food manufacturers producing products for these product categories are joining the Choices Foundation, resulting in a large availability of the logo in these product categories. As the Choices logo aims to stimulate a large availability of healthy products in all product categories, food manufacturers producing products for other categories should be stimulated to produce healthier products as well. Snacks, sauces and beverages largely contribute to the intake of energy, salt, added sugar and SFA in The Netherlands ${ }^{(30,31)}$ and could therefore be important categories for product innovation.

\section{Reported logo use v. actual logo use}

Participants who reported having intentionally purchased products with the logo, had indeed purchased more 
products with the logo than participants reporting not having done so. However, we observed that $17 \%$ of the food purchases of participants who reported not to purchase products with the logo, representing $71 \%$ of the participants, did carry the logo. This finding suggests that consumers often purchase products with the logo unintentionally, which is supported by earlier research using self-reported data ${ }^{(13)}$. Although the Choices logo aims to intentionally facilitate consumers in making healthy choices, the increased availability of healthier products might help to improve the dietary pattern of both intentional and unintentional shoppers.

\section{Food choice motives and logo use}

We found that those participants who reported paying considerable attention to their weight and also those who reported looking at nutrition information on food packages both stated that they purchase and do actually purchase more products with the Choices logo. To our knowledge, there is only one study that has investigated the predictors of actual use of a nutrition logo by collecting grocery store receipts ${ }^{(17)}$. Those authors found that participants who reported limiting their fat intake purchased more products with a nutrition logo. These findings suggest that health-conscious and weight-conscious people purchase more products with a nutrition logo, in agreement with studies using self-reported data ${ }^{(9,13,19,20)}$. However, based on our observational data, we are not able to conclude whether health-conscious and weight-conscious participants purchase logo products due to the logo, or due to another reason. Future research should make use of innovative research techniques such as eye tracking to study whether consumers purchase logo products due to the logo. The eye-tracking method measures eye movements to investigate which product characteristics are noticed when standing before the shelves in the supermarket. A disadvantage of this method is that participants have to wear an eyetracking apparatus when walking through the supermarket, possibly biasing the results. Also, eye movements could be unconscious, hampering the interpretation of the data. Other research types such as qualitative research by means of interviews could further provide deeper insights into why consumers purchase logo products.

Although we cannot attribute product purchases to the logo, we can conclude that health-conscious participants purchase more products with a healthier product composition. However, the Choices logo aims to stimulate a favourable eating pattern among all consumers. Those consumer groups that need to improve their dietary pattern should be reached in particular, such as people with lower levels of education or a high BMI. However, these consumers appear to be precisely the ones that are difficult to reach through nutrition education ${ }^{(30,32)}$. Future communication around the logo should be focusing on these specific target groups in order to help them to improve their dietary pattern.
Furthermore, the finding that making a shopping list was negatively associated with reported logo use is interesting. Possibly, a shopping list helps to focus on specific products during shopping and makes a consumer less susceptible to on-package and in-store nutrition information.

The finding that the higher enjoyment of the taste of food (hedonism) is rated, the fewer products with the logo are actually bought, can be explained by earlier studies: consumers seem to prefer foods that they perceive as unhealthy because they assume that such food tastes better and will give them more pleasure ${ }^{(33,34)}$. Thus, if one would like to motivate hedonists to adopt a healthier dietary pattern by purchasing healthier products, extra attention should be paid to the perceived tastefulness and image of healthy products.

\section{Study limitations}

A limitation of the present study is the low response rate. Because consumers were asked to participate in the study after having paid at the cash desk in the supermarket, many wanted to go home and indicated that they had no time to participate. However, by asking the consumers after having paid, we did not influence purchasing decisions, which was essential for the validity of the study data. Moreover, by measuring during both weekend days and evening hours, we tried to create a study population that is as representative as possible. Another limitation is that the food choice motive hedonism was measured by self-developed items based on earlier research ${ }^{(7)}$. The Cronbach's $\alpha$ of hedonism, together with some other food choice motives, was below $0 \cdot 7$, which is usually considered minimally acceptable. It would be recommended to validate these scales in future studies linking food choice motives to purchasing behaviour.

Also, not all products that comply with the Choices criteria currently bear the Choices logo, because producers join the Choices Foundation on a voluntary basis. We tried to correct for this by choosing one of the largest supermarket chains in The Netherlands and one that has joined the Choices Foundation. Nevertheless, by only choosing C1000 chain stores, the results of the study were limited to only one store chain and thus care should be taken when extrapolating the results to the general population. Another limitation is that inter-observer reliability was not assessed. Although the observers worked in pairs of two persons and both persons checked which products a participant just bought and whether the products were carrying a logo or not, testing inter-observer reliability would have added extra value to the quality of the collected data. A final limitation is that the study provides information about logo use based on only one shopping occasion, rather than about habitual shopping habits. Consequently, we recommend future studies to follow participants' food purchases over time to get more insight into the role of habitual purchasing 
behaviour, for example by asking them to scan all their food purchases for some weeks with a scanner.

There are hardly any studies that go beyond studying self-reported use of nutrition logos. Notwithstanding, these are frequently cited to support the existence of current nutrition $\operatorname{logos}{ }^{(9,15-17)}$. The current study is the first that has investigated the actual use of the Choices logo in the point-of-purchase setting. The innovative methodology used in the study, a combination of selfreported data and real-life observations, provides unique first insights into the actual use of the Choices nutrition logo and the related food choice motives of consumers. These insights can be used for tailoring health communication around the logo to subgroups of consumers, thereby possibly improving their dietary pattern ${ }^{(13,35)}$. Further intervention studies in point-of-purchase settings are needed to investigate the effectiveness of the Choices logo on food choices and health behaviour.

\section{Conclusion}

The Choices logo seems to mainly play a role in the actual food purchases of people who are health-conscious and weight-conscious. Hedonism or pleasure appears to be negatively associated with purchasing products with the logo. Thus, in order to stimulate all consumers to purchase more products with a favourable product composition, extra attention should be paid to the tastefulness and the image of healthy products.

\section{Acknowledgements}

This study was funded by the Choices Foundation. There were no conflicts of interest. The authors' responsibilities were as follows. E.L.V. developed the design, analysed the data and wrote the manuscript. I.H.M.S. developed the design and reviewed and critiqued the manuscript. J.A.V., A.W., M.G.H. and D.H.L. collected and analysed the data. J.B. and J.C.S. reviewed and critiqued the manuscript. All authors played a role in data interpretation and writing of the manuscript and approved the final version of the manuscript.

\section{References}

1. World Health Organization (2003) Diet, Nutrition and the Prevention of Chronic Diseases. Joint WHO/FAO Expert Consultation. WHO Technical Report Series no. 916. Geneva: WHO.

2. Steptoe A, Pollard TM \& Wardle J (1995) Development of a measure of the motives underlying the selection of food: the food choice questionnaire. Appetite 25, 267-284.

3. Brunsø K \& Grunert K (1995) Development and testing of a crossculturally valid instrument: food-related lifestyle. $A d v$ Consum Res 22, 475-480.

4. Hoek AC, Luning PA, Stafleu A et al. (2004) Food-related lifestyle and health attitudes of Dutch vegetarians, non- vegetarian consumers of meat substitutes, and meat consumers. Appetite 42, 265-272.

5. Scholderer J, Brunso K, Bredahl L et al. (2004) Crosscultural validity of the food-related lifestyles instrument (FRL) within Western Europe. Appetite 42, 197-211.

6. Glanz K, Kristal AR, Sorensen G et al. (1993) Development and validation of measures of psychosocial factors influencing fat- and fiber-related dietary behavior. Prev Med 22, 373-387.

7. Roininen K, Lahteenmaki L \& Tuorila H (1999) Quantification of consumer attitudes to health and hedonic characteristics of foods. Appetite 33, 71-88.

8. European Food Information Council (2005) Nutrition Information \& Food Labelling: Results of the EUFIC Consumer Research. Brussels: EUFIC.

9. Grunert KG \& Wills JM (2007) A review of European research on consumer response to nutrition information on food labels. J Public Health 15, 384-399.

10. Feunekes GI, Gortemaker IA, Willems AA et al. (2008) Front-of-pack nutrition labelling: testing effectiveness of different nutrition labelling formats front-of-pack in four European countries. Appetite 50, 57-70.

11. Stockley L (2007) Review of 'Front of Pack' Nutrition Schemes. Brussels: European Heart Network.

12. Young L \& Swinburn B (2002) Impact of the Pick the Tick food information programme on the salt content of food in New Zealand. Health Promot Int 17, 13-19.

13. Vyth EL, Steenhuis IHM, Mallant SF et al. (2009) A frontof-pack nutrition logo: a quantitative and qualitative process evaluation in the Netherlands. $J$ Health Commun 14, 631-645.

14. Dötsch-Klerk M \& Jansen L (2008) The Choices programme: a simple, front-of-pack stamp making healthy choices easy. Asia Pac J Clin Nutr 17, 383-386.

15. Grunert KG \& Wills JM (2008) Pan-European Consumer Research on In-store Observation, Understanding \& Use of Nutrition Information on Food Labels, Combined with Assessing Nutrition Knowledge. Brussels: European Food Information Council.

16. Rayner M, Boaz A \& Higginson C (2001) Consumer use of health-related endorsements on food labels in the United Kingdom and Australia. J Nutr Educ 33, 24-30.

17. Reid RD, Slovinec D'Angelo ME et al. (2004) The Heart and Stroke Foundation of Canada's Health Check food information program: modelling program effects on consumer behaviour and dietary practices. Can J Public Health 95, 146-150.

18. Aase S (2007) Supermarket trends: how increased demand for healthful products and services will affect food and nutrition professionals. J Am Diet Assoc 107, 1286-1288.

19. Mhurchu CN \& Gorton D (2007) Nutrition labels and claims in New Zealand and Australia: a review of use and understanding. Aust N Z J Public Health 31, 105-112.

20. Signal L, Lanumata T, Robinson JA et al. (2008) Perceptions of New Zealand nutrition labels by Maori, Pacific and lowincome shoppers. Public Health Nutr 11, 706-713.

21. Crossley ML \& Khan SN (2001) Motives underlying food choice: dentists, porters and dietary health promotion. Br Dent J 191, 198-202.

22. Pollard J, Greenwood D, Kirk S et al. (2002) Motivations for fruit and vegetable consumption in the UK Women's Cohort Study. Public Health Nutr 5, 479-486.

23. Pollard TM, Steptoe A \& Wardle J (1998) Motives underlying healthy eating: using the Food Choice Questionnaire to explain variation in dietary intake. J Biosoc Sci 30, 165-179.

24. Verweij A (2008) Indeling opleidingsniveau. In Volksgezondheid Toekomst Verkenning, Nationaal Kompas Volksgezondheid. Bilthoven: RIVM. http://www.nationaalkompas.nl/ bevolking/scholing-en-opleiding/ (accessed May 2009). 
25. The European Consumers' Organisation (2005) Report on European Consumers' Perception of Foodstuffs Labelling. Brussels: BEUC.

26. Cowburn G \& Stockley L (2005) Consumer understanding and use of nutrition labelling: a systematic review. Public Health Nutr 8, 21-28.

27. Croft J, Harris F \& Hayward W (2002) Health Claims on Food Packaging: Consumer Related Qualitative Research. London: Food Standards Agency.

28. Synovate (2005) Quantitative Evaluation of Alternative Food Signposting Concepts. London: Food Standards Agency.

29. Ree M, Riediger N \& Moghadasian MH (2008) Factors affecting food selection in Canadian population. Eur J Clin Nutr 62, 1255-1262.

30. The Netherlands Nutrition Centre (2005) Nederland in balans: Masterplan preventie overgewicht 2005-2010. The Hague: The Netherlands Nutrition Centre.
31. Wendel-Vos GCW, Nooyens ACJ \& Schuit AJ (2004) De bijdrage van leefstijl aan gewichtsstijging bij jongvolwassenen. Bilthoven: RIVM.

32. Verkleij H \& van Kreijl C (2004) Beïnvloedbaarheid van de voeding. In Ons eten gemeten, pp. 89-91 [C van Kreijl and A Knaap, editors]. Houten: Bohn Stafleu van Loghum.

33. Raghunathan R, Naylor RW \& Hoyer WD (2006) The unhealthy $=$ tasty intuition and its effects on taste inferences, enjoyment, and choice of food products. J Mark 70, 170-184.

34. Verbeke W (2006) Functional foods: consumer willingness to compromise on taste for health? Food Qual Prefer 17, 126-131.

35. Brug J, Oenema A \& Campbell M (2003) Past, present, and future of computer-tailored nutrition education. Am J Clin Nutr 77, 4 Suppl., 1028S-1034S. 